Egyptian

Orthodontic Journal

\title{
EVALUATION OF SHEAR BOND STRENGTH AND ADHESIVE REMNANT INDEX OF CERAMIC BRACKETS USING ONE-STEP SELF-ADHESIVE COMPOSITE RESIN
}

\author{
Essam Abdallah, ${ }^{1}$ Nadia El Harouni, ${ }^{1}$ \\ Amal Ezz El-Din Fahmy, ${ }^{2}$ Aly Osman ${ }^{3}$
}

ABSTRACT

Introduction: The purpose of this study was to evaluate and compare in Vitro the shear bond strength and adhesive remnant index of both Ice brackets and Clarity brackets bonded with Transbond XT vs Vertise flow self-adhesive composite using light emitting diode. Methods: Sixty extracted sound premolars were divided into 2 groups. Group I were bonded using Clarity brackets; 15 samples were bonded using light cure Transbond XT (IA) and 15 samples using self-adhesive Vertise flow (IB). Group II were bonded using Inspire Ice brackets using some previous techniques (IIA \& IIB). All the samples were then subjected to thermo cycling. The samples were stored in distilled water at $37^{\circ} \mathrm{C}$ for 24 hours. All the samples were subjected to shear bond strength testing using a Universal Testing Machine at a crosshead speed $0.5 \mathrm{~mm} / \mathrm{min}$. Then the de-bonded samples were examined under light Stereomicroscope to evaluate the adhesive remnant index of the samples. Descriptive statistics were displayed as means, standard deviation, minimum, maximum and median values for shear bond strength in MPa. Results: The shear bond strength (SBS) for the new flow able self-adhesive composite $(1 \mathrm{MPa}+0.99)$ was very low compared to the Transbond XT (18 MPa + 8.09) and to the clinically optimum SBS. The Clarity brackets showed greater SBS than the Inspire ICE brackets bonded with Transbond XT composite. The ARI index of the new self-adhesive composite showed with the Clarity brackets mostly score 3, while with Inspire Ice brackets the ARI index

1- Professor of Orthodontics. Faculty of Dentistry. Alexandria University.

2- Professor of Dental Biomaterials. Faculty of Dentistry. Alexandria University.

3- Post - graduate student. Orthodontic department Faculty of Dentistry. Alexandria University.

Volume 44 - December 2013 
Egyptian

Orthodontic Journal

was mostly score 5. Conclusion: The overall comparison showed that the new self-adhesive composite produced a very low SBS lower than the clinically accepted range for bonding orthodontic brackets than the Transbond XT due to difference in the technique of application.

\section{INTRODUCTION}

Buonocore $^{1}$ (1963) introduced the technology that eventually lead to the concept of direct bonding in orthodontics. Ten years later, Newman ${ }^{2}$ described a technique for acid-etching enamel to enhance the mechanical adhesion of orthodontic brackets to the teeth. Since then several factors that affect the mechanical adhesion of orthodontic brackets to the teeth have been described. Mills(1995) $)^{3}$ proposed the use of light-emitting diode (LED) technology for the polymerization of light initiated dental materials to overcome the shortcomings of halogen light-curing units. LED has a lifetime over 10,000 hours and undergoes little degradation of output over this time.

A wide variety of visible light-cured orthodontic adhesives have become available. ${ }^{4}$ Among the composite resins that could be used in orthodontics as bonding agents today, flowable composite (2005) merits great attention because of its clinical handling characteristics. Flowable composites show two desirable clinical handling characteristics that were not available for composites until very recently: (1) nonstickiness, so that materials could be packed or condensed, and (2) fluid injectability. ${ }^{5}$

Recently (2009), an innovative resin-based material, combining the properties of self-adhesion and flowability was developed, (Vertise flow, Kerr), introducing a new category of material defined as "self-adhering composite resin." These single-bottle systems are chemically based on a complex mixture of hydrophilic and hydrophobic monomers in water and organic solvents. Their adhesion process is based on the self-etch approach and combines etching, priming and bonding into a single applications step. ${ }^{7,8}$ The exclusion of rinsing and drying steps is indeed an attractive clinical advantage of all in-one system, since contamination risk is reduced and the bonding procedure is less sensitive to possible over-drying or over-wetting. ${ }^{9,10}$

In the mid-1980s, the first brackets made of monocrystalline sapphire and polycrystalline ceramic materials became widely available. ${ }^{11,12}$ Ceramic brackets are more esthetic than metal brackets, and 
Egyptian

Orthodontic Journal

unlike plastic brackets, they resist staining and discoloration. In-vitro studies with ceramic brackets reported extremely high bond strengths. ${ }^{13}$ The aim of this study was to evaluate and compare in Vitro the shear bond strength and adhesive remnants index of Ice brackets bonded with Transbond XT and Vertise flow composite using light emitting diode and the Clarity brackets bonded with Transbond XT and Vertise flow composite using light emitting diode.

\section{MATERIAL AND METHODS}

The selected sample of this in-vitro study consisted of sixty extracted human first upper and lower premolars collected from patients seeking orthodontic treatment whose treatment plan indicated extraction of maxillary and/or mandibular premolars.

\section{Materials}

Materials used in this study were:

\section{A) Brackets}

Two different types of orthodontic brackets for bonding were used:

1- Thirty Clarity ${ }^{*}$ ceramic brackets (Fig.1)

2- Thirty Inspire ICE ${ }^{* *}$ ceramic brackets (Fig.2)

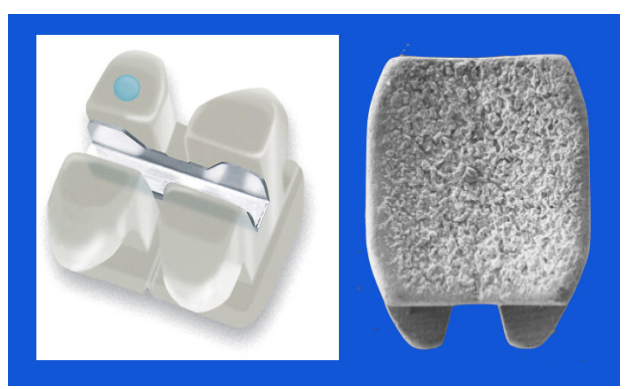

Fig. (1): Clarity Ceramic Brackets $\&$ base design

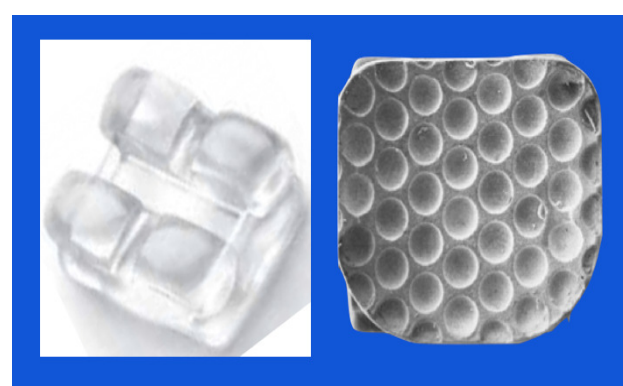

Fig: (2): Inspire ICE bracket $\&$ base design

* 3M Unitek Orthodontic Products, 2724 South Peck Road Monrovia, CA 91016 USA

** Ormco Corporation 1717 West Collins Orange, CA 9286 
Egyptian

Orthodontic Journal

B) Adhesives:

\begin{tabular}{|c|c|}
\hline Brand Name & Composition \\
\hline Transbond $\mathrm{XT}^{*}$ & $\begin{array}{l}\text { - Silane-treated quartz: } 70 \%-80 \% \\
\text { - Bisphenol A bis (2-hydroxyethyl ether) dimethacrylate }\end{array}$ \\
\hline Transbond XT primer* & $\begin{array}{l}\text { - Triethylene Glycol Dimethacrylate } 45-55 \% \\
\text { - Bisphenol A Diglycidyl ether Dimethacrylate } 45-55 \%\end{array}$ \\
\hline Etching gel $* *$ & •Phosphoric acid etching gel (37\%) \\
\hline Vertise Flow*** & $\begin{array}{l}\text { - Resin: GPDM adhesive monomer (Glycerol phosphate } \\
\text { dimethacrylate) } \\
\text { Filler: } \\
\text { - Prepolymerized filler containing } 0.7 \text { um barium glass filler } \\
\text { - 1um barium glass } \\
\text { - } 10-40 \mathrm{~nm} \text { nano-sized colloidal silica } \\
\text { - } 40 \mathrm{~nm} \text { nano-sized Ytterbium flouride }\end{array}$ \\
\hline
\end{tabular}

Grouping:

Group I: Thirty teeth bonded to Clarity ceramic brackets. This group was further subdivided into 2 sub-groups:

Group IA: Fifteen teeth etched using etching gel 37\% phosphoric acid then Transbond XT light cure composite.

Group IB: Fifteen teeth bonded using Vertise flow self-adhesive composite.

Group II: Thirty teeth bonded to Inspire Ice brackets. This group is further subdivided into 2 sub-groups:

Group IIA: Fifteen teeth etched using etching gel 37\% phosphoric acid then primed with the bonding agent followed by bonding of Inspire ICE brackets with Transbond XT light cure composite.

Group IIB: Fifteen teeth bonded using Vertise flow self-adhesive composite.

* 3M Unitek Orthodontic Products, 2724 South Peck Road Monrovia, CA 91016 USA

** 3M EPSE AG. Germany

*** Kerr corporation, 171 West collins Avenue, Orange, CA 92867 USA , (800) Kerr-123

Volume 44 - December 2013 
Egyptian

Orthodontic Journal

\section{Method:}

Each tooth was scaled and a thorough prophylaxis with pumice on a rubber cup mounted on a slow-speed, contra-angle hand-piece will be performed. The teeth will be rinsed thoroughly and dried.

\section{Acid etching and application of bonding agent:}

For groups IA \& IIA: The enamel surface was etched for 30 seconds with $37 \%$ phosphoric acid gel. After the 30 seconds etching the enamel surface was then rinsed thoroughly with an air water syringe for 20 seconds in order to wash the enamel surface from the residual etchant. The etched surface was then dried with the air syringe until the buccal surface of the teeth appeared chalky white. Transbond XT primer was painted onto the etched surface using a disposable brush to apply the primer.

Application of bonding material and bracket placement:

For groups IA \& IIA: Fifteen Clarity brackets and 15 Inspire ICE brackets were bonded to the enamel surface using light cure Transbond XT composite.

For groups IB \& IIB: 15 Clarity brackets and 15 Inspire ICE brackets were bonded to the enamel surface using light cure self-adhesive Vertise flow composite.

The adhesive was then cured through its exposure to the light curing source using light emitting diode (LED) curing light. ${ }^{*}$ Each bracket was exposed to the light for 10 seconds according to the manufacturer's instruction.

\section{Thermocycling}

All samples were thermocycled in a water bath for 500 cycles using the thermocycling machine, alternating between $5^{\circ} \mathrm{C}$ and $55^{\circ} \mathrm{C}$ with dwell time 30 seconds. After themocycling, the samples were stored in distilled water at $37^{\circ} \mathrm{C}$ for 24 hours to prevent their dehydration until they were tested in shear.

* Ledex TM WL-070, Dentmate (Intensity 1000mw/cm2, wave length 440nm-480nm) 
Egyptian

Orthodontic Journal

Shear bond strength testing:

All the specimens were used for shear bond strength testing. Each tooth within its acrylic block were placed in the split copper ring, and then the copper ring was inserted in the copper mold and fixed firmly with the screws. The tapered rod was connected to the load cell to be towards the buccal surface of the tooth, the copper mold was then adjusted and fixed to the base of the Universal testing machine. The crosshead speed was adjusted at $0.5 \mathrm{~mm} / \mathrm{min}$.

The bond strength was calculated in megapascals using the formula:

$$
\text { Bond strength }(\mathrm{MPa})=\frac{\text { Force in newtons }(\mathrm{N})}{\text { Surface area of brackets }\left(\mathrm{mm}^{2}\right)}
$$

The surface area of the brackets were $11.82 \mathrm{~mm}^{2}$ for the Clarity and $11.67 \mathrm{~mm}^{2}$ for the Inspire ICE, as given by the manufacturer.

\section{Adhesive remnants Evaluation:}

Premolars from each group were examined under Olympus light stereomicroscope $^{* *}$ at $40 \mathrm{x}$ magnification for evaluation of the ARI after bond failure. Photographs were taken using a digital camera ${ }^{* * *}$ and the area of the adhesive remnants was calculated for each tooth using micro image processing software ${ }^{* * *}$. Afterward, each tooth was assessed using modified Adhesive Remnant Index (ARI) value according to the following scores ${ }^{(14)}$ :

Score 1: all of the composite remained on the tooth surface.

Score 2: more than $90 \%$ of composite remained on the tooth surface.

Score 3: more than $10 \%$ but less than $90 \%$ of composite remained on the tooth surface.

Score 4: less than $10 \%$ of composite remained on the tooth surface.

Score 5: indicates that no composite remained on the tooth surface.

\footnotetext{
* (Commten Industries Florida -USA)

** Olympus SZ -CTV, Japan

*** Panasonic, WV-CP230/G, Germany

**** Soft imaging system sis, analysis, Gmbh, German
} 
Egyptian

Orthodontic Journal

\section{STATISTICAL ANALYSIS}

Descriptive statistics were displayed as means, standard deviation, minimum, maximum and median values for shear bond strength in MPa. Normality of distribution of shear bond strength was assessed by Kolmogrov Smirnov test and the variable was found to be not normally distributed. The median was used for comparison because the variables are not normally distributed, this is why also a non-parametric test (Kruskall wallis) was used.

\section{RESULTS}

Table I shows median shear bond strengths in MPa among the 4 groups. In group IA where Transbond XT was used to bond the Clarity brackets, the median shear bond strength was $18 \pm 8.09 \mathrm{MPa}$. In group IB where Vertise Flow adhesive used to bond the Clarity brackets, the median shear bond strength was $1 \pm 0.99 \mathrm{MPa}$. In group IIA where Transbond XT used to bond the Ice Brackets showed shear bond strength of $13 \pm 6.5 \mathrm{MPa}$. While in group IIB where Vertise Flow adhesive was used to bond the Ice brackets showed the shear bond strength of $1 \pm 0.86 \mathrm{MPa}$.

Table I: The median shear bond strengths in MPa, standard deviation and minimum and maximum values for the four groups.

\begin{tabular}{|l|c|c|c|c|}
\hline \multirow{2}{*}{} & \multicolumn{2}{|c|}{ Group I (Clarity) } & \multicolumn{2}{c|}{ Group II (Inspire Ice) } \\
\cline { 2 - 5 } & $\begin{array}{c}\text { Transbond XT } \\
\text { (subgroup 1A) }\end{array}$ & $\begin{array}{c}\text { Vertise Flow } \\
\text { (subgroup 1B) }\end{array}$ & $\begin{array}{c}\text { Transbond XT } \\
\text { (subgroup 2A) }\end{array}$ & $\begin{array}{c}\text { Vertise Flow } \\
\text { (subgroup 2B) }\end{array}$ \\
\hline Min- max & $13-34$ & $0-4$ & $7-27$ & $0-3$ \\
\hline Median & $18.00^{\mathrm{a}}$ & $1.00^{\mathrm{b}}$ & $13.00^{\mathrm{c}}$ & $1.00^{\mathrm{b}}$ \\
\hline Mean & 21.47 & 1.40 & 13.00 & 1.20 \\
\hline SD & 8.09 & 0.99 & 6.50 & 0.86 \\
\hline $\begin{array}{l}\mathrm{X}^{2} \text { of Kruskal } \\
\text { Wallis test } \\
\text { P value }\end{array}$ & \multicolumn{5}{|c|}{46.84} \\
\hline
\end{tabular}

*: Statistically significant at $\mathrm{P} \leq 0.05$

$\mathrm{a}, \mathrm{b}$ and $\mathrm{c}$ : different letters denoting significant differences

Volume 44 - December 2013 
Egyptian

Orthodontic Journal

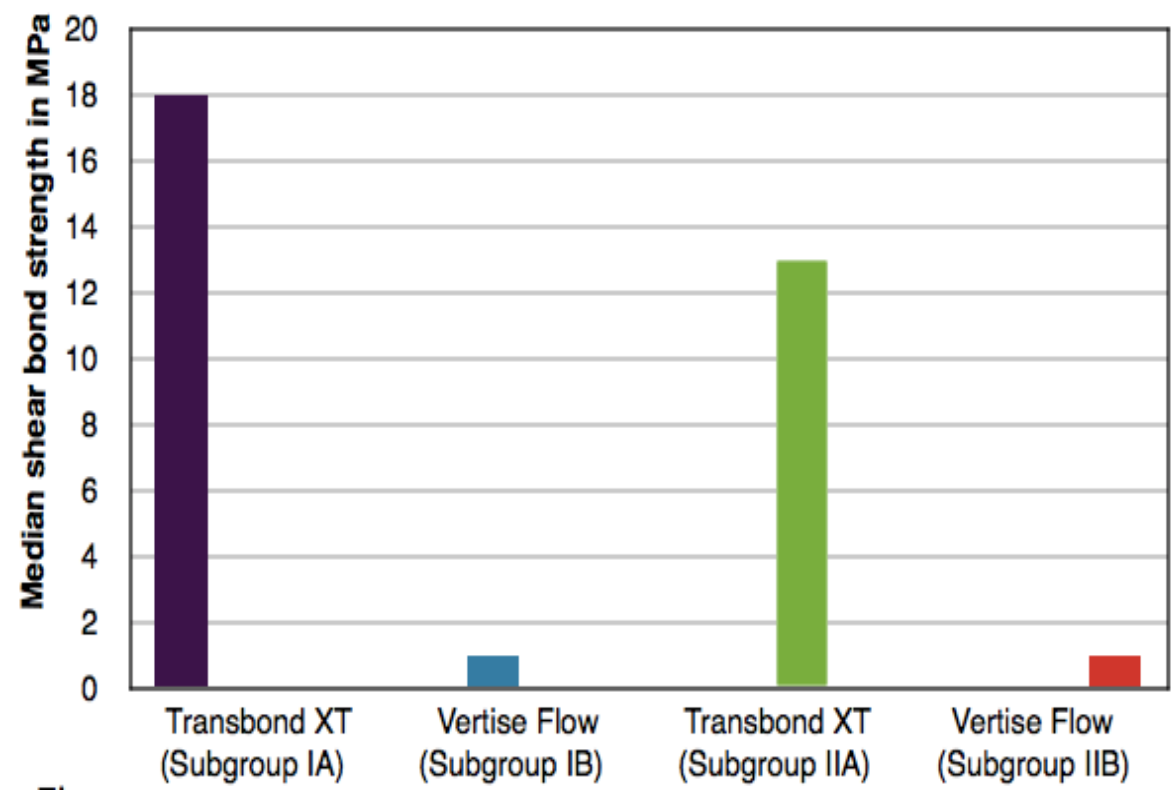

Graph (1): Bar chart showing the median SBS in $\mathrm{MPa}$ among the study group

Table II shows the Adhesive Remnant Indices of the four groups examined under stereomicroscope and the Chi-square comparisons showed that the four groups had significantly different ARI scores. The Chi-square comparisons between Vertise Flow and Transbond XT used for bonding Clarity brackets showed no statistically significant difference, While the Chi-square comparisons between Vertise Flow and Transbond XT used to bond ICE brackets showed a statistically significant difference. There was a significant difference between the Clarity group and the Inspire ICE group. 
Egyptian

Orthodontic Journal

Table II: Comparison of ARI among the four groups

\begin{tabular}{|l|c|c|c|c|}
\hline \multirow{2}{*}{} & \multicolumn{2}{|c|}{ Group I (Clarity) } & \multicolumn{2}{c|}{ Group II (Inspire Ice) } \\
\cline { 2 - 5 } & $\begin{array}{c}\text { Transbond XT } \\
\text { (subgroup 1A) }\end{array}$ & $\begin{array}{c}\text { Vertise Flow } \\
\text { (subgroup 1B) }\end{array}$ & $\begin{array}{c}\text { Transbond XT } \\
\text { (subgroup 2A) }\end{array}$ & $\begin{array}{c}\text { Vertise Flow } \\
\text { (subgroup 2B) }\end{array}$ \\
\hline Score 1 & 0 & 0 & 0 & 0 \\
\hline Score 2 & 0 & 0 & 0 & 0 \\
\hline Score 3 & $11(73.3 \%)$ & $14(93.3 \%)$ & 0 & $1(6.7 \%)$ \\
\hline Score 4 & $4(26.7 \%)$ & $1(6.7 \%)$ & $1(6.7 \%)$ & $5(33.3 \%)$ \\
\hline Score 5 & 0 & 0 & $14(93.3 \%)$ & $9(60 \%)$ \\
\hline Min- max & $3-4$ & $3-4$ & $4-5$ & $3-5$ \\
\hline Median & Score 3 & Score 3 & Score 5 ${ }^{\text {a }}$ & Score 5 \\
\hline $\begin{array}{l}X^{2} \text { of Kruskal } \\
\text { Wallis test } \\
\text { P value }\end{array}$ & \multicolumn{4}{c}{46.25} \\
\hline
\end{tabular}

*: Statistically significant at $\mathrm{P} \leq 0.05$

$\mathrm{a}, \mathrm{b}$ and $\mathrm{c}$ : different letters denoting significant differences

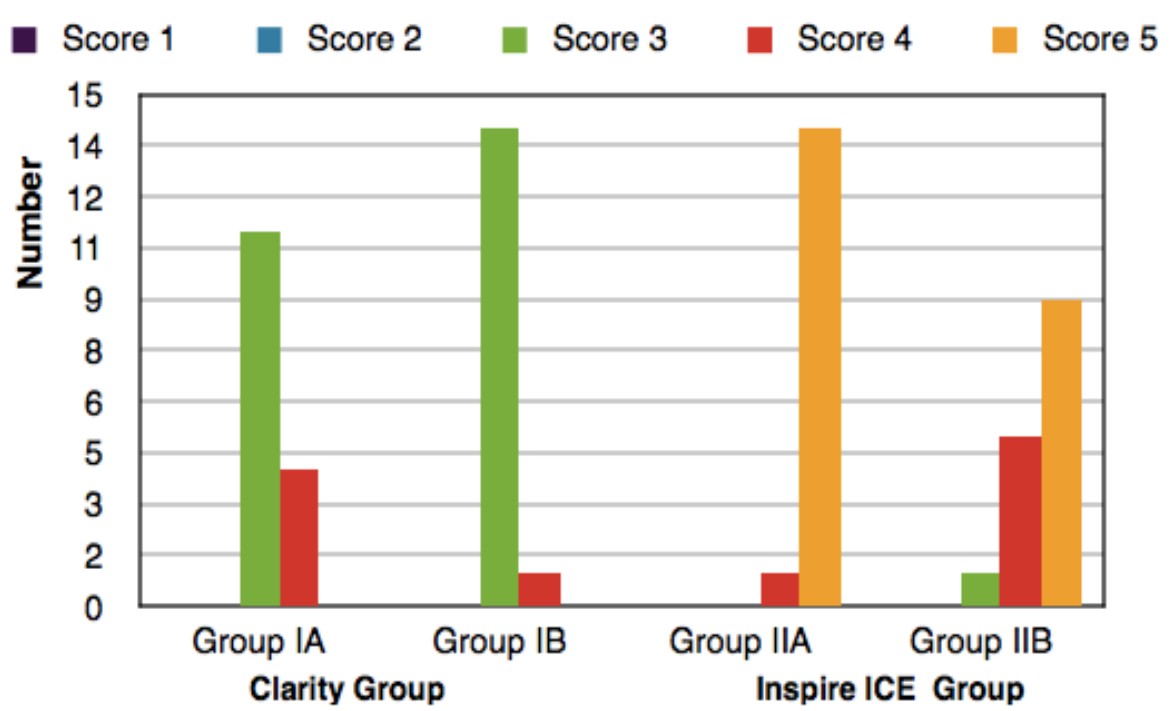

Graph (2): Bar chart showing the ARI index among the study groups 
Table III shows the failure sites among the 4 groups. In group I most of the failure occurred is cohesive failure. (ie; within the adhesive), while in group II most of the failure occurred at the enamel-adhesive interface. There was a statistically significant difference between group I Clarity brackets and group II Inspire Ice brackets where $\mathrm{P}<0.0001$.

Table III: Comparison of failure site of the four groups

\begin{tabular}{|l|c|c|c|c|}
\hline \multirow{2}{*}{ Failure site } & \multicolumn{2}{|c|}{ Group I (Clarity) } & \multicolumn{2}{c|}{ Group II (Inspire Ice) } \\
\cline { 2 - 5 } & $\begin{array}{c}\text { Transbond XT } \\
\text { (subgroup 1A) }\end{array}$ & $\begin{array}{c}\text { Vertise Flow } \\
(\text { subgroup 1B) }\end{array}$ & $\begin{array}{c}\text { Transbond XT } \\
\text { (subgroup 2A) }\end{array}$ & $\begin{array}{c}\text { Vertise Flow } \\
(\text { subgroup 2B) }\end{array}$ \\
\hline Bracket- adhesive & 0 & 0 & 0 & 0 \\
\hline Cohesive-failure & $15(100 \%)$ & $15(100 \%)$ & $1(6.7 \%)$ & $6(40 \%)$ \\
\hline Enamel- adhesive & 0 & 0 & $14(93.3 \%)$ & $9(60 \%)$ \\
\hline $\begin{array}{l}X^{2} \\
\text { P value }\end{array}$ & \multicolumn{5}{|c|}{40.82} \\
\end{tabular}

*: Statistically significant at $\mathrm{P} \leq 0.05$

$\mathrm{a}, \mathrm{b}$ and $\mathrm{c}$ : different letters denoting significant differences

- Bracket-Adhesive

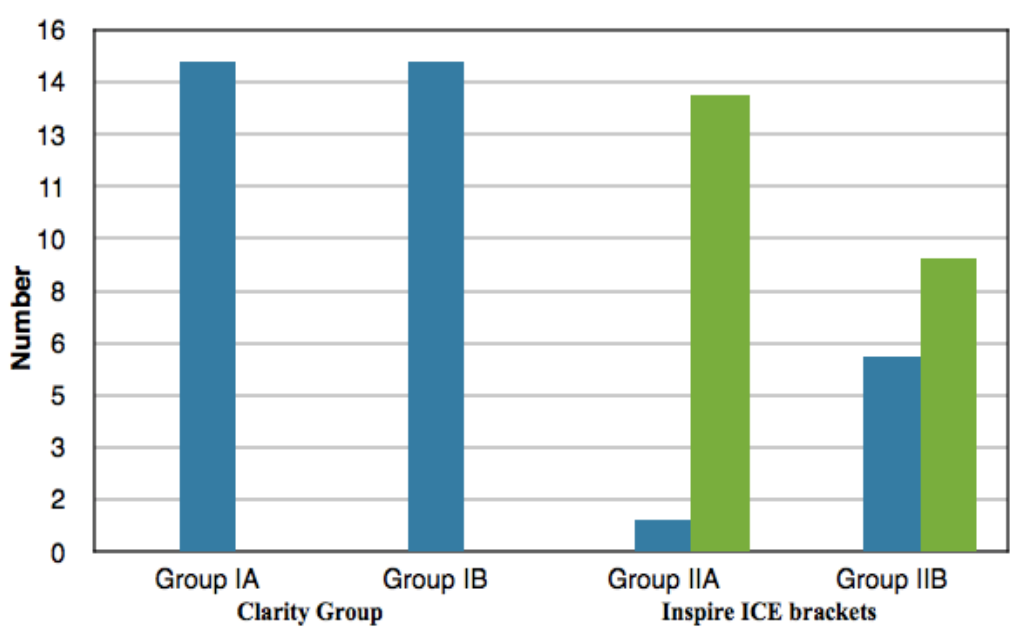

Graph (3): Bar chart showing the sites of failure among the study groups 


\section{Egyptian}

Orthodontic Journal

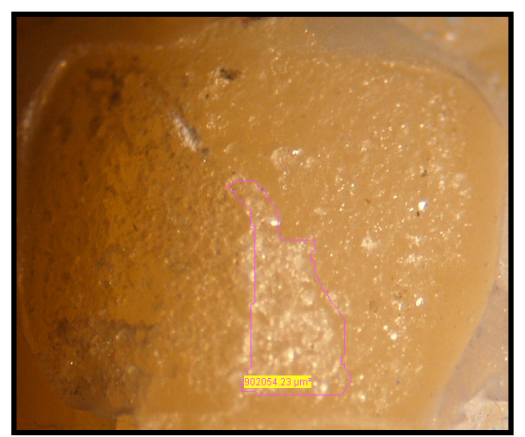

Fig.(10): Stereomicroscopic image showing enamel surface after de-bonding Clarity bracket using Transbond XT composite. ARI shown in the image is score 3.(Adhesive remained on the tooth between 10 and 90\%)

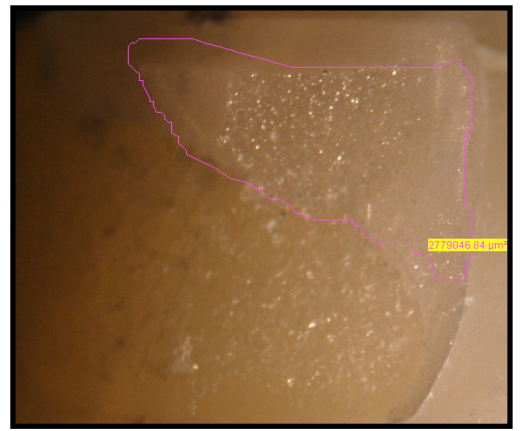

Fig.(11): Stereomicroscope image showing enamel surface after de-bonding Clarity bracket using Vertise Flow composite. ARI shown in the image is score 3; where no adhesive remained on the tooth surface

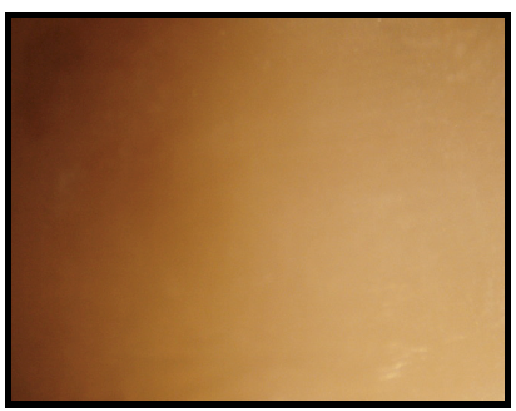

Fig.(12): Stereomicroscopic image showing enamel surface after de-bonding Inspire ICE bracket using Transbond XT composite. ARI shown in the image is score 5; where no adhesive remained on the tooth surface 
Egyptian

Orthodontic Journal

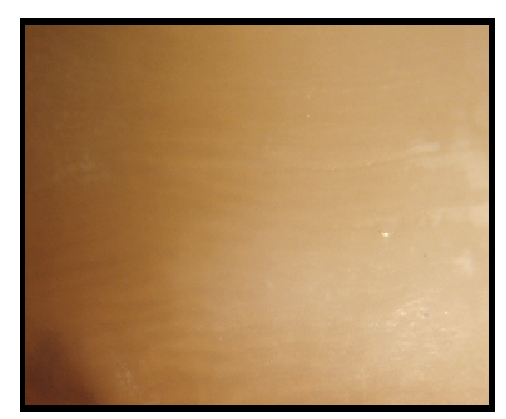

Fig.(13): Stereomicroscopic image showing enamel surface after de-bonding Inspire ICE bracket using Vertis Flow composite. ARI shown in the image is score 5; where no adhesive remained on the tooth surface.

\section{DISCUSSION}

Some researchers have suggested that a minimum SBS of $8.0 \mathrm{MPa}$ is adequate for bonding orthodontic brackets to teeth. ${ }^{15}$ Bishara et al reported that SBS of $7 \mathrm{MPa}$ was clinically acceptable for bonding to the enamel surface. ${ }^{16}$ The maximum bond strength of an orthodontic bracket should be less than the breaking strength of enamel, which is about $14 \mathrm{MPa}{ }^{17}$

In the present study the self-adhesive resin produced a significantly lower shear bond strength (1MPa) compared with the conventional Transbond XT (18 MPa). This may be attributed to the fact that Vertise Flow is one-step self-adhesive resin, where the brackets are bonded directly to the tooth surface without etching of the tooth surface, and the use of low viscosity primer. On the other hand, Transbond XT bonds the brackets in the conventional three-step procedure.

Also, it may be due to difference in the type of acidic monomer used for each adhesive. In Vertise Flow the acidic monomer is GDPM which possess an initial $\mathrm{pH}$ of 2, while Transbond XT uses phosphoric acid for etching which has very low pH 0.7 to 1.2. Hence has higher dissolving capacity to the hydroxyapatite and result in longer resin tags and increasing the shear bond strength. ${ }^{18}$ 
In agreement with the results of this study, Tancan et al ${ }^{19}$ evaluated three different types of flowable adhesives (Pulpdent Flows-Rite, 3M Filtek Flow, and Heraeus Kulzert Flow Line) and compared them with the conventional Transbond XT adhesive for bonding orthodontic metallic brackets. The results of this study concluded that the shear bond strength of the Transbond XT was significantly higher than the flowable adhesives. The shear bond strength of these flowable adhesives was slightly higher than the Vertise Flow used in the current study, however it is still below the clinically acceptable shear bond strength for orthodontic bonding. This may be due to the use of etching procedure as a separate step before bonding with the flowable adhesives.

On the other hand, Simona et $\mathrm{al}^{5}$ investigated a new flowable composite Denfil Flow and reported a SBS value of $34.8 \mathrm{MPa}$. This may be due to the difference in the brackets used in this study which were metal brackets and the different composition of the composite Denfil and the Vertise Flow adhesive.

Bracket failure at the bracket/adhesive interface is advantageous because it leaves the enamel surface relatively protected during debonding; however, considerable chair time is needed to remove the residual adhesive and may be accompanied by a degree of enamel loss. ${ }^{20}$

In the current study the results of the ARI scores and percentage of adhesive remaining on tooth surface area showed a significant difference between group I Clarity brackets and group II Inspire ICE brackets. Comparing ARI scores between teeth bonded using Transbond XT versus Vertise flow composite showed no statistically significant difference. In group I Clarity brackets showed some adhesive remaining on the tooth surface as the bracket failure is mostly cohesive failure (score 3-4). However in group II Inspire ICE brackets showed almost no adhesive remained on the tooth surface as the bracket failure is mostly at enameladhesive interface (score 5). This may be attributed to the difference in the base design between the two brackets, the Clarity bracket has rough surface and the Inspire ICE bracket base has ball-base design. Lina et al ${ }^{21}$ found greater incidence of failure at bracket-adhesive interface using Transbond XT for both Clarity and Inspire ICE brackets where most of the adhesive remained on the enamel. These results were different from 
Egyptian

Orthodontic Journal

the results of the present study. This may be attributed to the use of different light curing unit, halogen type instead of LED used in the current study. Bishara et $\mathrm{al}^{22}$ and Mundstock et $\mathrm{al}^{23}$ found high incidence of ARI score 1 (all adhesive on the enamel) with the Clarity brackets bonded with Transbond XT and showed no enamel damage in any of the teeth. (i.e: failure at the bracket-adhesive interface) This may be due to the use higher crosshead speed during the debonding of the brackets in the universal testing machine $(5 \mathrm{~mm} / \mathrm{min})$ instead of $0.5 \mathrm{~mm} / \mathrm{min}$ used in the current study. Also, the samples were not thermocycled before debonding. For enamel fractures, there was no evidence that self-adhesive resin cements produce enamel fractures or cracks which may be due to their low shear bond strength which was less than optimum in the current and some of the previous studies.

\section{CONCLUSION}

The overall comparison showed that the new self-adhesive composite produced a very low SBS lower than the clinically accepted range for bonding orthodontic brackets than the Transbond XT due to difference in the technique of application, (i.e: one-step Vs three-step procedure).

In case of the ARI, the Clarity brackets bonded by both types of adhesives showed mainly score 3 (i.e: failure site is cohesive) while Inspire ICE brackets bonded by both types of adhesives showed mainly score 5 (i.e: failure site is enamel-adhesive), this may be due to the difference in the bracket base design between the two brackets.

\section{REFERENCES}

1- Buonocore MC. Principles of adhesive retention and adhesive restorative materials. J Am Dent Assoc. 1963;67:382-391.

2- Newman GV. Current status of bonding attachments. J Clin Orthod. 1973;7:425-449.

3- Mills RW. Blue light emitting diodes-another method of light curing? Br Dent J 1995; 178:169.

4- Tancan Uysal, Zafer Sari, Abdullah Demir. Are the flowable composites suitable for orthodontic bracket bonding. Angle Orthod 2004;74:697-702. 
5- Simona Teccoa; Tonino Trainib; Sergio Caputic; Felice Festad; Valentina de Lucae; Michele D'AttiliofA new one-step dental flowable composite for orthodontic use. Angle Orthod 2005;75:672-677.

6- Alessandro Vichi, Cecilia Goracci, Marco Ferrari. Clinical study of the self-adhering flowable composite resin Vertise flow in class I restoration. International dentistry journal 2009

7- Kugel G, Ferrari M. The science of bonding: from first to sixth generation. J Am Dent Assoc, 2000-20S-25S.

8- Van Landuyt KL, Peumans M, De Munck J, Lambrechts P, Van Meerbeek B. Extension of a one-step self-etch adhesive into a multistep adhesive. Dent Mater, 2006. 22(6): p. 533-44.

9- Tay FR, Gwinnett AJ, Pang KM, Wei SH. Resin permeation into acidconditioned, moist, and dry dentin: a paradigm using water-free adhesive primers. J Dent Res, 1996. 75(4): p. 1034-44.

10- Tay FR,Gwinnett JA, Wei SH. Micromorphological spectrum from overdrying to overwetting acid-conditioned dentin in waterfree aceton-based, single-bottle primer/adhesives. Dent Mater, 1996. 12(4): p. 236-44.

11- Winchester LJ. Bond strengths of five different ceramic brackets: an in-vitro study. Eur J Orthod 1991;13:293-305.

12- Harris AM, Joseph VP, Rossouw PE. Shear peel bond strengths of esthetic orthodontic brackets. Am J Orthod Dentofacial Orthop 1992;102:215-9.

13- Odegaard J, Segner D. Shear bond strengths of metal brackets compared with a new ceramic bracket. Am J Orthod Dentofacial Orthop 1988;94:201-6.

14- Tancan H, Uysal T, Sari Z, Demir A. Are the flowable composites suitable for orthodontic bracket bonding? Angle Orthod 2004;74:697-702

15- Leung Y, Morris MD. Characterization of the chemical interactions between 4-MET and enamel by Raman spectroscopy. Dent. Mater J 1995;11(3):191-195 
16- Bishara SE, Gordan VV, VonWald L, Jakobsen JR. Shear bond strength of composite, glass ionomer and acidic primer adhesive systems. Am J Orthod Dent. Orthop 1999;115:24-8

17- Pickett KL, Sadowsky PL, Jacobson A, Lacefield W. Orthodontic in vivo bond strength: comparison with in vitro results. Angle Orthod 2001;71:141-148

18- Pashley DH, Tay FR. Aggressiveness of contemporary self-etching adhesives, part II: etching on unground enamel. Dent Mater $2001 ; 17: 430-44$

19- Tancan U, Zafer S. Are the flowable composites suitable for orthodontic bracket bonding? Angle Orthod. 2004;74:697-702

20- Zachrisson B. Cause and prevention of injuries to teeth and supporting structures during orthodontic treatment. Am J Orthod $1976 ; 69 ; 285-300$

21- Theodorakopoulou LP, Sadowsky PL, Jacobson A, Lacefield W Jr. Evaluation of the de-bonding characteristics of 2 ceramic brackets. Am J Orthod Dentofacial Orhop 2004;125:329-36

22- Bishara SE, Olsen ME, VonWald L, Jakobsen JR. Comparison of the debonding characteristics of two innovative ceramic bracket design. Am J Orthod Dentofacial Orthop 1999;116:86-92

23- Mundstock KS, Sadowsky PL, Lacefield W, Bae S. An in vitro evaluation of metal reinforced orthodontic ceramic bracket. Am J Orthod Dentofacial Orthop 1999;116:635-41 